\title{
Effect of Low Temperature on the Termination of Photoperiodic and Food-Mediated Diapause in the Cabbage Bug, Eurydema rugosa Motschulsky (Heteroptera: Pentatomidae)
}

\author{
Kayoko IKeDA-KIKUE ${ }^{1}$ and Hideharu Numata \\ Department of Biology, Faculty of Science, Osaka City University, \\ Sumiyoshi-ku, Osaka 558, Japan
}

(Received 10 September, 1993; Accepted 17 November, 1993)

\begin{abstract}
In Eurydema rugosa, adult diapause was induced under short-day conditions, with rape seeds or leaves as food, or under long-day conditions with rape seeds as food. Exposure to low temperature or long-day conditions with leaves terminated the diapause induced by short-day conditions with leaves. The diapause induced under short-day conditions on seeds can be also terminated by exposure to a low temperature. However, these treatments did not terminate the diapause induced by feeding on seeds under long-day conditions. The diapause induced under short-day conditions is suggested to be terminated by the low temperatures during winter under natural conditions.
\end{abstract}

Key words: Eurydema rugosa, diet, photoperiod, low temperature, diapause development

\section{INTRODUCTION}

Nymphs of Eurydema rugosa reared under long-day conditions on rape leaves became reproductive adults, whereas those reared under long-day conditions on rape seeds, and those reared under short-day conditions on rape seeds or leaves, became diapause adults (Numata and Yамамото, 1990). In the field, both the nymphs growing on seeds of crucifers in spring and those growing in late summer on leaves became diapause adults (Ikeda-Kikue and Numata, unpublished).

In some insects, the intensity of diapause depends on the environmental conditions during the induction of diapause (see Danks, 1987). Furthermore, in the cabbage moth, Mamestra brassicae, in central or southern Japan, not only the intensity but also the thermal requirement for termination depends on the photoperiodic conditions during the induction of the pupal diapause (MASAKI, 1956). Therefore, it is of interest to compare the environmental factors that control the diapause development among different photoperiodic and food conditions during the induction of the adult diapause in E. rugosa.

In this study, we examined the effect of diapause-averting conditions, i.e., long-day conditions with leaves and the effect of low temperature on the diapause development, and divided the diapause in E. rugosa into two types, i.e., short-day diapause and foodmediated diapause, according to the mode of diapause development.

1 Present address: Department of Biology, International Christian University, Mitaka, Tokyo 181, Japan 


\section{MATERIALS AND METHODS}

Adults of Eurydema rugosa were collected on the brown mustard, Brassica juncea in Tawaramoto $\left(34^{\circ} 30^{\prime} \mathrm{N}, 35^{\circ} 45^{\prime} \mathrm{E}\right)$, Nara Prefecture, Japan. The first generation, i.e., the eggs laid by the field-collected adults, or the second generation in the laboratory were used for the experiments. Insects were reared in groups, at $25 \pm 1{ }^{\circ} \mathrm{C}$ under short-day conditions (10L-14D), on leaves or seeds of the rape, Brassica napus, or under long-day conditions $(16 \mathrm{~L}-8 \mathrm{D})$ on rape seeds. The rearing density was maintained in the second instar at about 12 per plastic cup $(200 \mathrm{ml})$, or about 45 per plastic pot $(1,000 \mathrm{ml})$, and in the adult stage at 8 or less per cup, or 20 or less per pot. Under these photoperiodic and food conditions, the insects entered adult diapause (Numata and Yамамото, 1990). These adults became inactive about 10 days after emergence, and thereafter they rarely fed or walked about. Twenty days after emergence, the diapause adults were provided for the following experiments.

Diapause adults were transferred into conditions of $16 \mathrm{~L}-8 \mathrm{D}$ at $25^{\circ} \mathrm{C}$, with leaves or seeds, and reared as male and female pairs in $200-\mathrm{ml}$ plastic cups. Some adults were kept under the same diapause-inducing conditions as controls. In the next experiment, diapause adults were exposed to $10 \pm 2^{\circ} \mathrm{C}$ and $10 \mathrm{~L}-14 \mathrm{D}$ for 90 days. At $10^{\circ} \mathrm{C}$, only water was supplied. Then they were returned to $25^{\circ} \mathrm{C}$ and reared as male and female pairs on rape leaves or seeds under $16 \mathrm{~L}-8 \mathrm{D}$ or $10 \mathrm{~L}-14 \mathrm{D}$. Mating and oviposition were recorded daily.

The females that had not laid eggs and the males that had not mated for a set number of days were dissected. The females with yolk deposition were judged as diapause-terminating adults, as were those that laid eggs. In males, when the ectodermal sac of the accessory gland was filled with secretory fluid, the insects were judged as diapause-terminating adults, as were those that mated (Numata and Yамамото, 1990).

\section{RESULTS}

When we reared $E$. rugosa for 150 days after adult emergence continuously on leaves under $10 \mathrm{~L}-14 \mathrm{D}$ at $25^{\circ} \mathrm{C}$, all the females had died without oviposition with the exception of three individuals (Fig. 1A). One of the three females began to lay eggs 44 days after emergence and died 59 days after emergence. The other two survived for 150 days without oviposition and were still in diapause. Thus, the diapause induced under 10L-14D on leaves did not terminate spontaneously without any change in environmental factors. When transferred to $16 \mathrm{~L}-8 \mathrm{D}$ on leaves, however, the surviving females began to lay eggs after 16-47 days (36-67 days after adult emergence), although about $60 \%$ of the females died without oviposition. No females were in diapause 47 days after the photoperiodic transfer (Fig. 1B). Thus, the diapause induced under 10L$14 \mathrm{D}$ on leaves was terminated by long-day conditions and leaves.

When we reared the $E$. rugosa continuously on seeds under $16 \mathrm{~L}-8 \mathrm{D}$ at $25^{\circ} \mathrm{C}$, most surviving females were still in diapause 150 days after adult emergence, and only a few females began to lay eggs 125-142 days after adult emergence (Fig. 1C). When the food was changed to leaves, some females began to lay eggs after 95-113 days (115133 days after adult emergence), although the others remained in diapause 150 days after adult emergence (Fig. ID). Thus, long-day conditions with leaves had no marked 


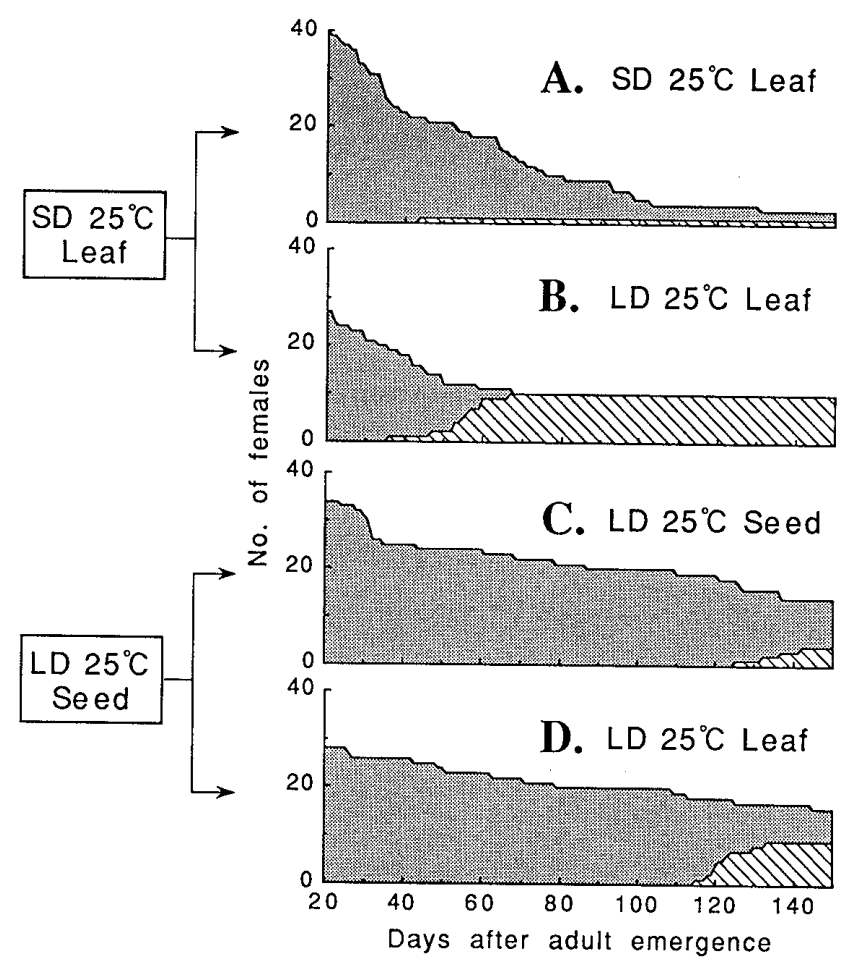

Fig. 1. Effect of photoperiod and diet on the termination of diapause induced under short-day conditions with rape leaves as food or under long-day conditions with rape seeds as food in E. rugosa. LD, 16L-8D; SD, 10L-14D. Hatched areas, cumulative ovipositing females; shaded areas, non-ovipositing females.

effect on the termination of the diapause induced by feeding on seeds.

Next, we transferred the adults in which diapause had been induced under $10 \mathrm{~L}-$ $14 \mathrm{D}$ on leaves to $16 \mathrm{~L}-8 \mathrm{D}$ on seeds. In this experiment, we examined the percentage of diapause termination 40 days after the transfer, i.e., 60 days after adult emergence, and therefore we show the results again when we changed only the photoperiodic conditions as a control. Transferred from short-day to long-day conditions without change of food, all females terminated diapause within 40 days (Fig. 2A). When we changed both photoperiodic and food conditions, however, about $50 \%$ of the adults were still in diapause 40 days after the transfer (Fig. 2B). The percentage of diapause termination was significantly different between the two dietary conditions in the females ( $p<0.05$, Fisher's exact probability test). Thus, the adults in which the diapause had been induced under short-day conditions on leaves were sensitive to dietary conditions.

Then, we exposed the diapause adults reared under 10L-14D on leaves to $10^{\circ} \mathrm{C}$ for 90 days and returned them to $25^{\circ} \mathrm{C}$ under $10 \mathrm{~L}-14 \mathrm{D}$ or $16 \mathrm{~L}-8 \mathrm{D}$ on leaves or seeds. In the experiments on the effect of low temperature, we show the percentage of diapause termination 40 days after the return to $25^{\circ} \mathrm{C}$. The mortality after returning to $25^{\circ} \mathrm{C}$ was higher on leaves than on seeds in both sexes under either photoperiodic condition. However, regardless of the photoperiodic and food conditions, all females laid eggs with the exception of only one individual (Fig. 3A-D). The median of the preoviposition period after return to $25^{\circ} \mathrm{C}$ was 14 or 15 days for each set of photoperiodic and food 


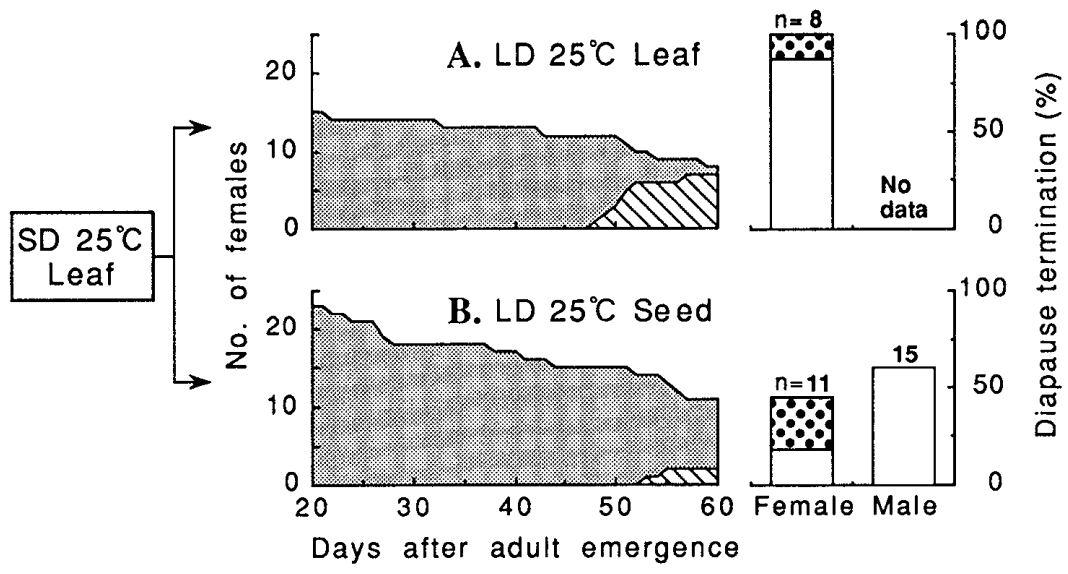

Fig. 2. Effect of photoperiod and diet on the termination of diapause induced under shortday conditions with rape leaves as food in E. rugosa. LD, 16L-8D; SD, 10L-14D. Hatched areas, cumulative ovipositing females; shaded areas, non-ovipositing females. Columns show the percentage of diapause termination 60 days after adult emergence, i.e., 40 days after transfer. Dotted column, non-ovipositing females with yolk deposition.

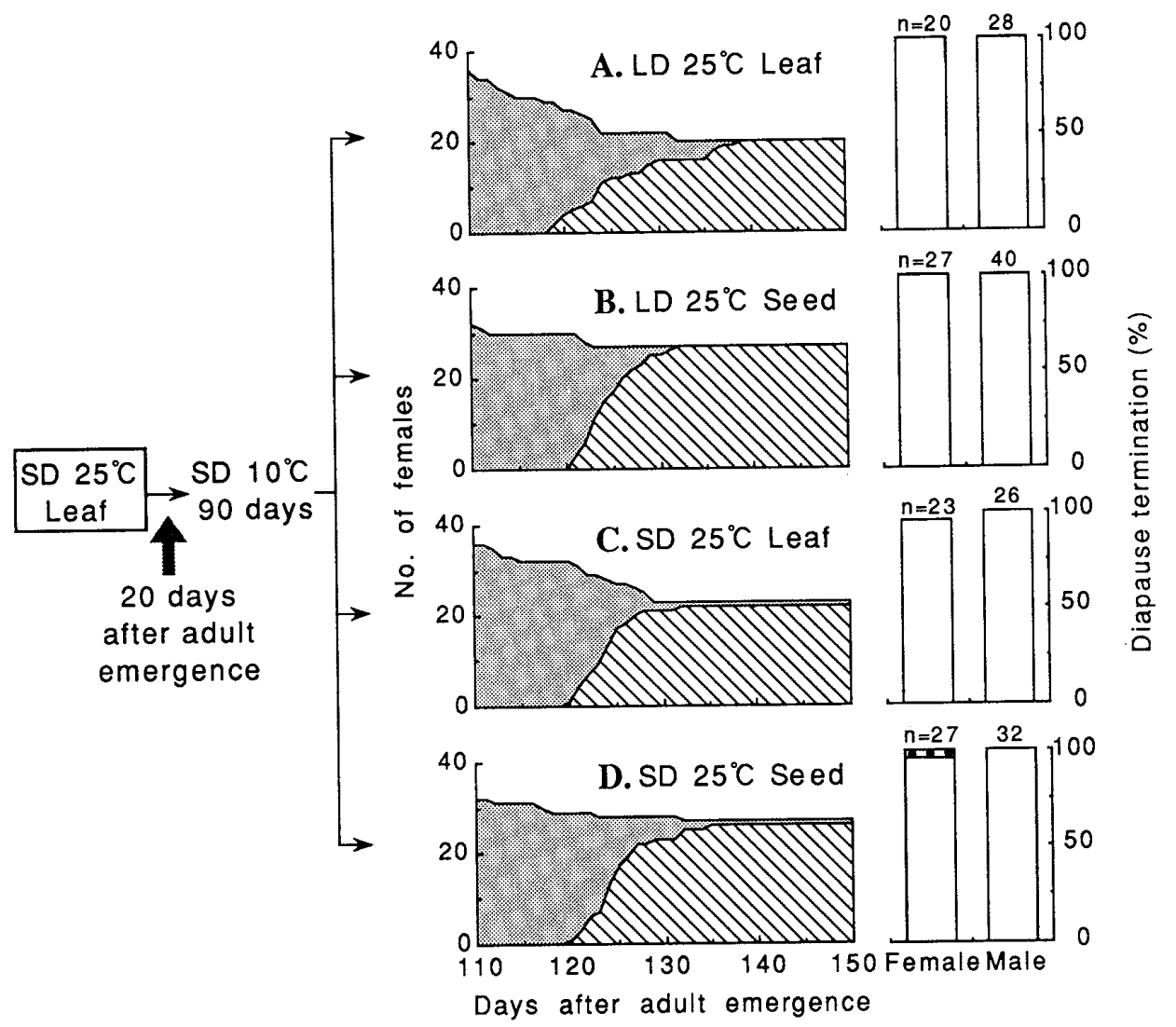

Fig. 3. Effect of low temperature on the termination of diapause induced under shortday conditions with rape leaves as food in E. rugosa. LD, 16L-8D; SD, 10L-14D. Hatched areas, cumulative ovipositing females; shaded areas, non-ovipositing females. Columns show the percentage of diapause termination 150 days after adult emergence. Dotted column, non-ovipositing females with yolk deposition, 
conditions. There was no significant difference in the preoviposition period among the conditions ( $H=1.057, p>0.7$, KRUSKaL-Wallis test). All males became reproductive, regardless of the photoperiodic and food conditions. Thus, these insects had completely lost the sensitivity to the photoperiod and to the nature of the food supplied after being exposed to $10^{\circ} \mathrm{C}$. Therefore, we conclude that the diapause induced under short-day conditions on leaves was terminated by the exposure to a low temperature.

In contrast, an exposure to $10^{\circ} \mathrm{C}$ had no marked effect on the termination of the diapause induced under $16 \mathrm{~L}-8 \mathrm{D}$ on seeds. When the diapause adults were transferred to $16 \mathrm{~L}-8 \mathrm{D}$ at $25^{\circ} \mathrm{C}$ after exposure to $10^{\circ} \mathrm{C}$, about $70 \%$ of adults maintained diapause whether the food was seeds or leaves (Fig. 4A, B). Several females began to lay eggs, although the preoviposition period was significantly longer than that of females in a diapause induced under short-day conditions, whether the food was seeds or leaves $(p<0.001$ for either type of food, ManN-Whitney test). When the diapause adults were transferred to $10 \mathrm{~L}-14 \mathrm{D}$ at $25^{\circ} \mathrm{C}$ after exposure to $10^{\circ} \mathrm{C}$, all or most of them maintained the diapause regardless of dietary conditions (Fig. 4C, D). Thus, an exposure to $10^{\circ} \mathrm{C}$ for 90 days was not sufficient to terminate this type of diapause or to remove the sensitivity to the photoperiod.

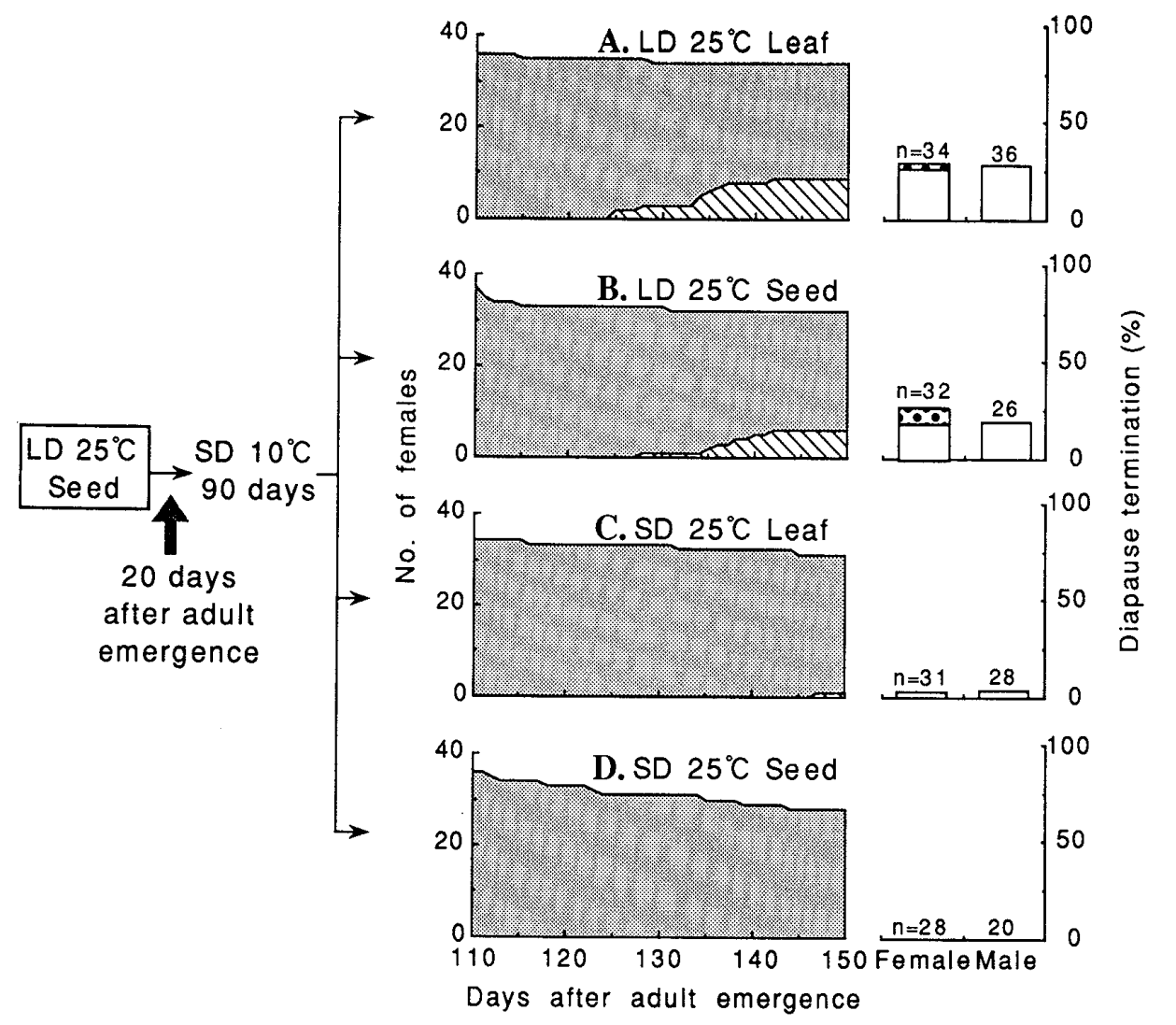

Fig. 4. Effect of low temperature on the termination of diapause induced under long-day conditions with rape seeds as food in E. rugosa. LD, 16L-8D; SD, 10L-14D. Hatched areas, cumulative ovipositing females; shaded areas, non-ovipositing females. Columns show the percentage of diapause termination 150 days after adult emergence. Dotted column, nonovipositing females with yolk deposition. 


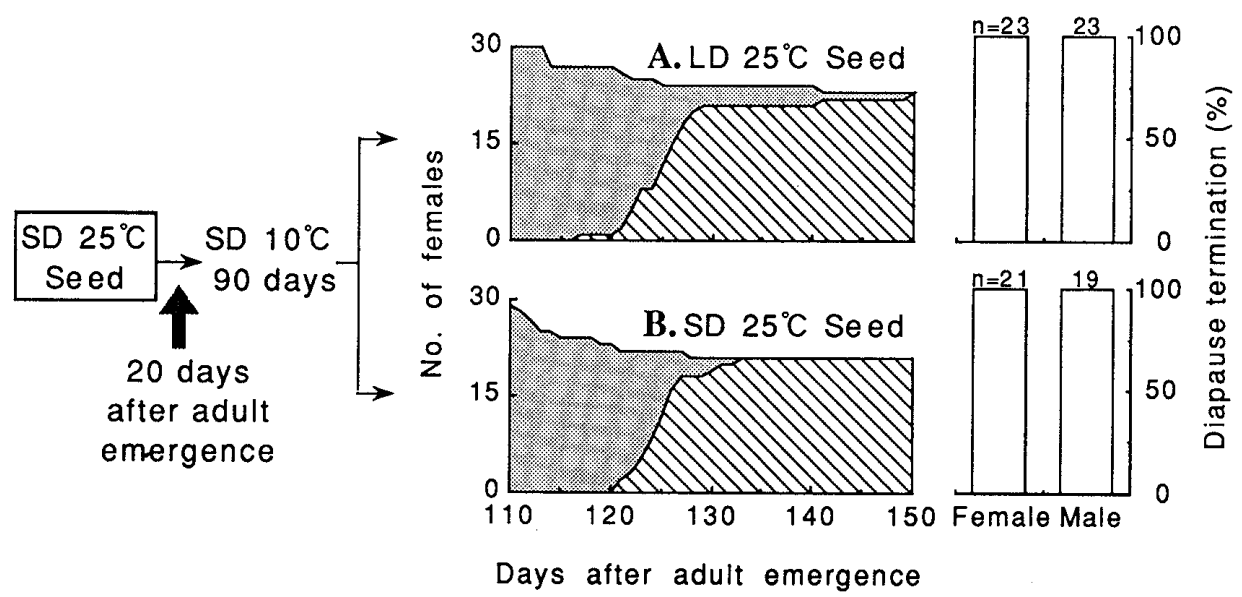

Fig. 5. Effect of low temperature on the termination of diapause induced under short-day conditions with rape seeds as food in E. rugosa. LD, 16L-8D; SD, 10L-14D. Hatched areas, cumulative ovipositing females; shaded areas, non-ovipositing females. Columns show the percentage of diapause termination 150 days after adult emergence.

Lastly, we transferred the diapause adults reared under $10 \mathrm{~L}-14 \mathrm{D}$ on seeds to $16 \mathrm{~L}-8 \mathrm{D}$ or $10 \mathrm{~L}-14 \mathrm{D}$ at $25^{\circ} \mathrm{C}$ on seeds after an exposure to $10^{\circ} \mathrm{C}$ for 90 days. They became reproductive both under long-day and under short-day conditions. The median of the preoviposition period was 15 days for either photoperiodic condition (Fig. 5A, B). There was no significant difference in the preoviposition period between the two conditions ( $p>0.8$, Mann-Whitney test). Thus, after exposure to a low temperature, these adults had lost their sensitivity to the photoperiod.

\section{DISCUSSION}

Low temperature terminated the diapause that had been induced under short-day conditions on leaves or seeds in all or most insects, although low temperature had no marked effect on the termination of diapause that had been induced under long-day conditions on seeds. Therefore, we can discriminate between two types of diapause in E. rugosa according to the mode of diapause development: One is terminated by low temperature, and the other is not. We can call the former short-day diapause and the latter food-mediated diapause, based on the factors of their induction. Numata and Yамамото (1990) showed that in the males of the E. rugosa there is a certain physiological difference between short-day and food-mediated diapause based on the size of their testes. In the present study, the response to low temperature confirmed that a certain physiological difference exists between short-day and food-mediated diapause in both sexes of $E$. rugosa.

Furthermore, all females terminated short-day diapause within 50 days after transfer to long-day conditions, although all females maintained food-mediated diapause for more than 90 days after the change of food from seeds to leaves. Thus, in $E$. rugosa, the response to diapause-averting conditions, i.e., long-day conditions with leaves, depended on the conditions during the induction of diapause, as did the response to low temperature, with respect to the termination of the diapause. 
The status of the host plant affects the induction of diapause in many insects. In general, deficient or less nutritious diets enhance the tendency to enter diapause (see Danks, 1987). However, in the pink bollworm, Pectinophora gossypiella, the fat content of food increases the incidence and duration of diapause under short-day conditions (Adxrsson et al., 1963; Foster and CROWder, 1980). Furthermore, in the phytophagous lady beetle, Henosepilachna vigintioctopunctata, under short-day conditions, the adults fed on low quantity or quality of food arrest their ovarian development but remain in the first stage of diapause in which they are sensitive to the photoperiod. Only when fed on sufficient amounts of suitable food, do the adults enter the second stage of diapause and lose the sensitivity to photoperiod (Kono, 1979, 1982). Thus in $H$. vigintioctopunctata, food conditions determine the physiological state of the diapause adults. In contrast, it was not food but photoperiodic conditions during the induction that determined the physiological state of the diapause adults in E. rugosa in which both these conditions controlled the induction of diapause.

Then we consider the factor for the termination of short-day diapause under natural conditions. We should not presume that the low temperature or long-day conditions which accelerate the diapause termination in the laboratory will also act to terminate the diapause in the field (TAUBER and TAUBER, 1976). In E. rugosa, short-day diapause did not terminate without a change in environmental conditions. Any change in environmental conditions is necessary for the termination. In the laboratory, either long-day conditions with leaves or a low temperature terminated this type of diapause. In the field, however, the short-day conditions in late summer, which induce the diapause, are not followed rapidly by long-day conditions. Moreover, the adults collected in early April were insensitive to the photoperiod and the diet (IKEDA-KIKUE and Numata, 1992). Therefore, in the field, it must be the low temperatures in winter that terminate the short-day diapause.

Moderate temperatures or short-day conditions usually terminate summer diapause induced under long-day conditions (see MASAKI, 1980). In E. rugosa also, these environmental conditions possibly terminate the food-mediated diapause induced under longday conditions. We are going to study the factors of termination in the food-mediated diapause.

\section{REFERENCES}

Adkisson, P. L., R. A. BeLl and S. G. Wellso (1963) Environmental factors controlling the induction of diapause in the pink bollworm, Pectinophora gossypiella (SAunders). J. Insect. Physiol. 9: 299-310.

Danks, H. V. (1987) Insect Dormancy: An Ecological Perspective. Biological Survey of Canada, Ottawa, $439 \mathrm{pp}$.

Foster, D. R. and L. A. Crowder (1980) Diapause of the pink bollworm, Pectinophora gossypiella (Saunders), related to dietary lipids. Comp. Biochem. Physiol. 65B : 723-726.

Ikeda-Kikue, K. and H. Numata (1992) Effects of diet, photoperiod and temperature on the postdiapause reproduction in the cabbage bug, Eurydema rugosa. Entomol. Exp. Appl. 64: 31-36.

Kono, Y. (1979) Abnormal photoperiodic and phototactic reactions of the beetle, Epilachna vigintioctopunctata, reared on sliced potatoes. Appl. Entomol. Zool. 14: 185-192.

Kono, Y. (1982) Changes of photoperiodic sensitivity with fat body development during prediapause period in the twenty-eight-spotted lady beetle, Henosepilachna vigintioctopunctata FABRIcius (Coleoptera: Coccinelidae). Appl. Entomol. Zool. 17: 92-101.

MasaKI, S. (1956) The local variation in the diapause pattern of the cabbage moth, Barathra brassicae Linné, with particular reference to the aestival diapause (Lepidoptera: Noctuidae). Bull. Fac. Agric. Mie Univ. 13: 29-46. 
Masaki, S. (1980) Summer diapause. Annu. Rev. Entomol. 25: 1-25.

Numata, H. and K. Yамамото (1990) Feeding on seeds induces diapause in the cabbage bug, Eurydema rugosa. Entomol. Exp. Appl. 57: 281-284.

TAuber, M. J. and C. A. TAuber (1976) Insect seasonality: diapause maintenance, termination, and postdiapause development. Annu. Rev. Entomol. 21 : 81-107. 